\title{
Controllable Synthesis of Silver Nanoparticles Using Three-Phase Flow Pulsating Mixing Microfluidic Chip
}

\author{
Guojun Liu $\left(\mathbb{D},,^{1}\right.$ Xiang Ma $\mathbb{D},{ }^{1}$ Xiaodong Sun $\mathbb{D}^{2},{ }^{2}$ Yanhui Jia $\mathbb{D}^{1},{ }^{1}$ and Tengfei Wang $\mathbb{D}^{1}$ \\ ${ }^{1}$ College of Mechanical Science and Engineering, Jilin University, Changchun 130025, China \\ ${ }^{2}$ College of Communication Engineering, Jilin University, Changchun 130025, China \\ Correspondence should be addressed to Yanhui Jia; jiayh@jlu.edu.cn
}

Received 7 November 2017; Revised 12 January 2018; Accepted 8 February 2018; Published 14 March 2018

Academic Editor: Fernando Lusquiños

Copyright (c) 2018 Guojun Liu et al. This is an open access article distributed under the Creative Commons Attribution License, which permits unrestricted use, distribution, and reproduction in any medium, provided the original work is properly cited.

On the basis of liquid-phase reduction mechanism, a novel synthesis method to prepare silver nanoparticles (AgNPs) is proposed, which uses piezoelectric-actuated three-phase flow pulsating mixing microfluidic chip. In order to study and explore the influence of different factors on the synthesis of AgNPs, a series of related synthesis experiments were carried out. The corresponding experimental conditions include the concentration of sodium hydroxide and reducing agent solution, polyvinylpyrrolidone (PVP) dosage, inlet flow rate, and synthesis temperature. The synthesized AgNPs were characterized by the UV-Vis absorption spectrophotometer and transmission electron microscopy. The effects of different experimental conditions on the controllable synthesis of AgNPs were analyzed, and the optimum synthesis conditions of AgNPs were obtained. Experimental results show that the spherical AgNPs with an average particle diameter of about $29 \mathrm{~nm}$, high yield, fine morphology, and good monodispersity were synthesized using the microfluidic chip under the conditions of the working frequency $(200 \mathrm{~Hz})$, the initial concentration of silver nitrate $(1 \mathrm{mM})$, the synthesis temperature $\left(80^{\circ} \mathrm{C}\right)$, the concentration ratio of sodium hydroxide to silver nitrate $(2: 1)$, the concentration ratio of glucose to silver nitrate $(4: 1)$, the inlet flow rate $(3.5 \mathrm{ml} / \mathrm{min})$, and the quality ratio of PVP to silver (more than $1: 1)$. The related research shows that it is an efficient synthesis method to develop the controllable synthesis experiments of AgNPs under multifactors using the three-phase pulsating mixing microfluidic chip.

\section{Introduction}

Silver nanoparticles (AgNPs), due to the volume effect, surface effect, quantum size effect, tunneling effect, and some new unique properties, are ideal candidates for biological [1], catalytic [2,3], agricultural [4], chemical sensor [5], chemical probe [6], and medical $[7,8]$ applications. However, the properties and applications of these nanoparticles mainly depend upon the shape, size, and distribution of nanoparticles [9]. Hence, how to prepare AgNPs with good performance is of vital importance.

Since the 21st century, there have been many new methods of preparing AgNPs in the world [10-14]. For example, Agrawal et al. [10] synthesized Ag and Al nanoparticles using an innovative approach of ultrasonic dissociation of thin films. Küünal et al. [11] reported on the study of surfactant-free silver nanoparticles synthesized using nonhydrolytic sol-gel methods. Roopan et al. [12] used mesocarp layer extract of Cocos nucifera as a reduction agent to synthesize silver nanoparticles. However, in recent years with the rapid development of microfluidic technology, the microfluidic chips based on microfluidic technology have been widely used in the synthesis of AgNPs due to their characteristics of low consumption of reagent, high reaction efficiency, controllable reaction process, and safe and reliable [15-18].

Compared to other synthetic methods, the synthesis of AgNPs by microfluidic chip effectively shortens the synthesis time, simplifies the preparation process, and enables the controllable synthesis of AgNPs. But the controllable synthesis of AgNPs is affected by many factors [19-23], and how to synthesize AgNPs with good performance by adjusting their influencing factors in microfluidic system is attracting more and more attention. Baber et al. [19] synthesized AgNPs with an average diameter of 3.1 9.3 nm and narrow size distribution by varying the concentration and 

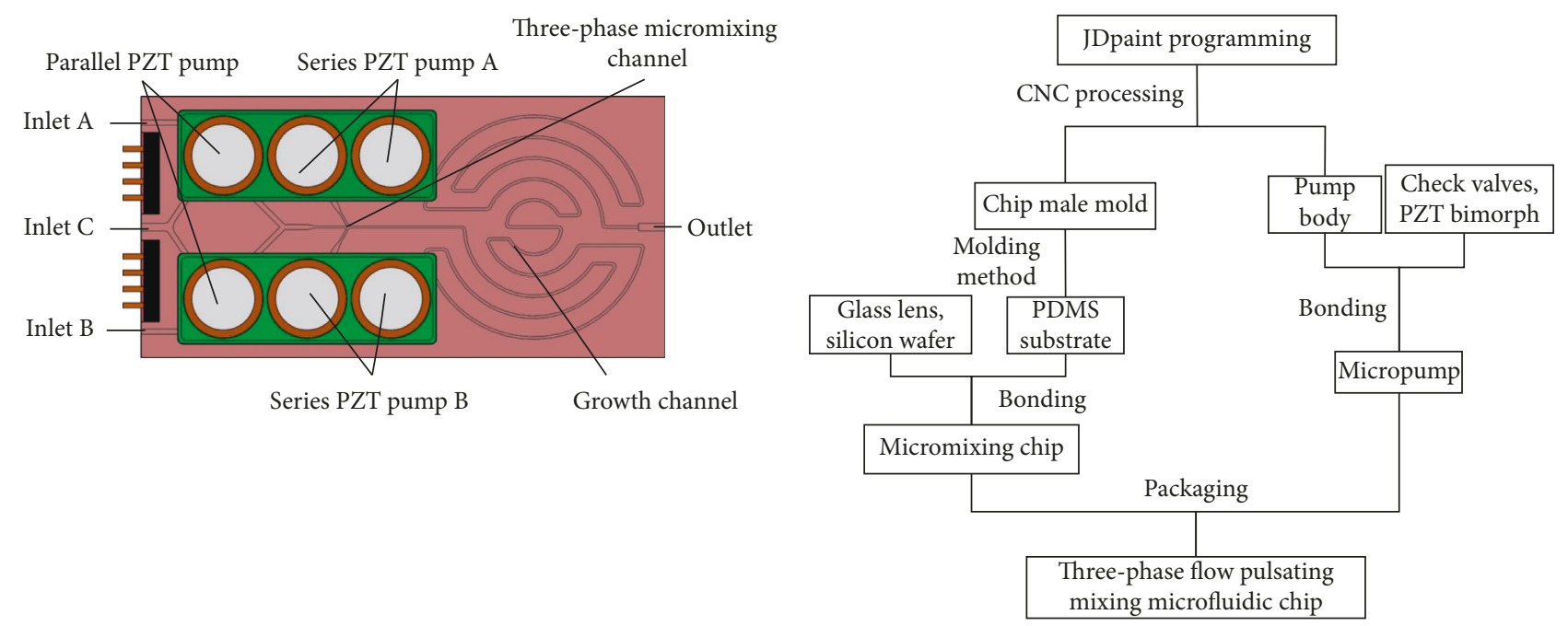

(a)

(b)

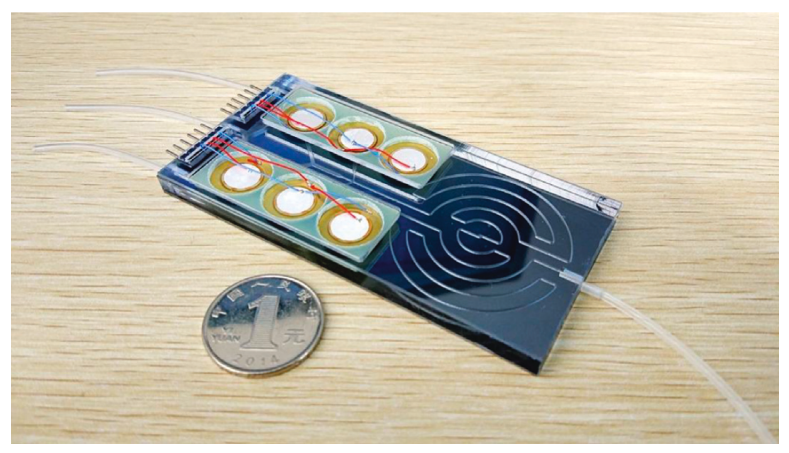

(c)

Figure 1: (a) The prototype schematic of the microfluidic chip. (b) The fabrication flowchart of microfluidic chip for three-phase flow pulsating mixing. (c) The prototype photo of the microfluidic chip.

flow rate of the reaction reagents in a coaxial flow reactor. They found that higher flow rates resulted in the appearance of larger AgNPs (as well as increased polydispersity), and higher silver nitrate concentrations will be increasing the likelihood of reactions occurring in silver nitrate-rich zones, which leads to an increased formation of larger nanoparticles and polydispersity. He et al. [20] synthesized AgNPs with different particle size and monodispersity by adjusting the reaction temperature and the flow rate of the precursor solution in the microfluidic device. Lazarus et al. [21] analyzed various flow conditions to determine optimal flow rates for producing gold and silver nanoparticles. They demonstrated that the combination of fast and controlled microfluidic mixing with ionic liquid solvents allows for the synthesis of high-quality, small, and monodisperse gold and silver nanoparticles in the microfluidic system. Yang et al. [22] synthesized AgNPs with uniform particle size by controlling the flow rate of the solution and chitosan concentrations in the microfluidic chip. They found that reducing the flow rate of the continuous phase or increasing the flow rate of the dispersed phase achieves a narrow size distribution of AgNPs, and they also revealed that the particle size increases with increasing chitosan concentration. Xu et al. [23] observed that an increase in the mean diameter of AgNPs with increasing fluid flow rates. However, AgNPs formed clusters at higher flow rates. In addition, they found that EDTA as a complexant presented significant effect on the morphology and particle size control of spherical AgNPs with good dispersion. Through experiments, they also proved that the controllable synthesis of AgNPs can be realized by using the microfluidic device.

It is clear from our literature survey that, on the basis of the microfluidic chip, the AgNPs with good performance can be synthesized controllably by changing the synthesis conditions of AgNPs. However, the current studies on the influencing factors of controllable synthesis of AgNPs by microfluidic devices are relatively simple. Besides, the microfluidic devices are mostly $\mathrm{Y}$ - or T-type which are driven by a syringe pump, and the operation of microfluidic devices are also more complicated. Based on the current situation, this paper presented a piezoelectric driven integrated three-phase pulsating mixing microfluidic chip, and the synthesis of silver nanoparticles were carried out by changing the synthesis parameters of silver nanoparticles. Analyzing the test results of UV-Vis absorption spectrophotometer (UV-Vis) and transmission electron microscopy (TEM), we discussed the effects of the concentration of sodium hydroxide $(\mathrm{NaOH})$ and glucose $\left(\mathrm{C}_{6} \mathrm{H}_{12} \mathrm{O}_{6}\right)$ solutions, polyvinylpyrrolidone (PVP) dosage, inlet flow rate 


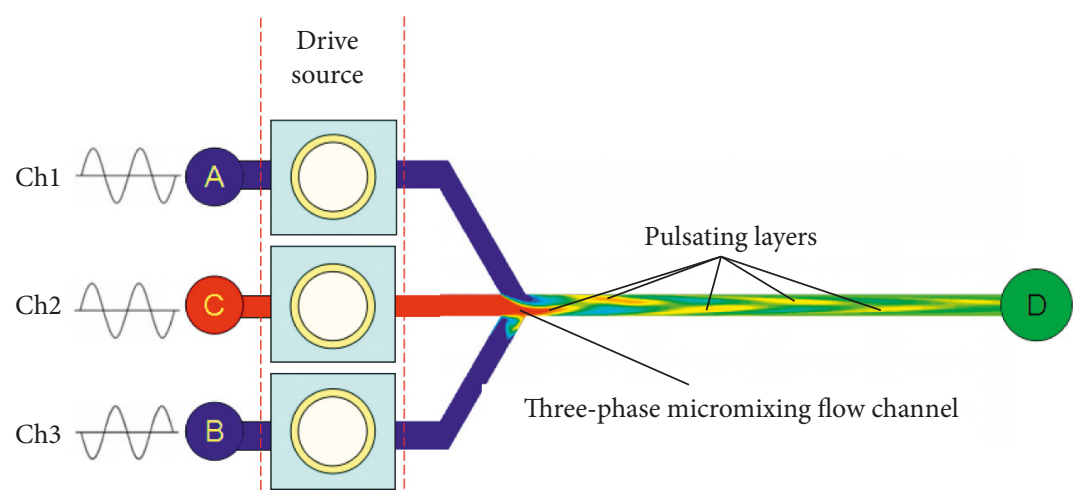

(a)

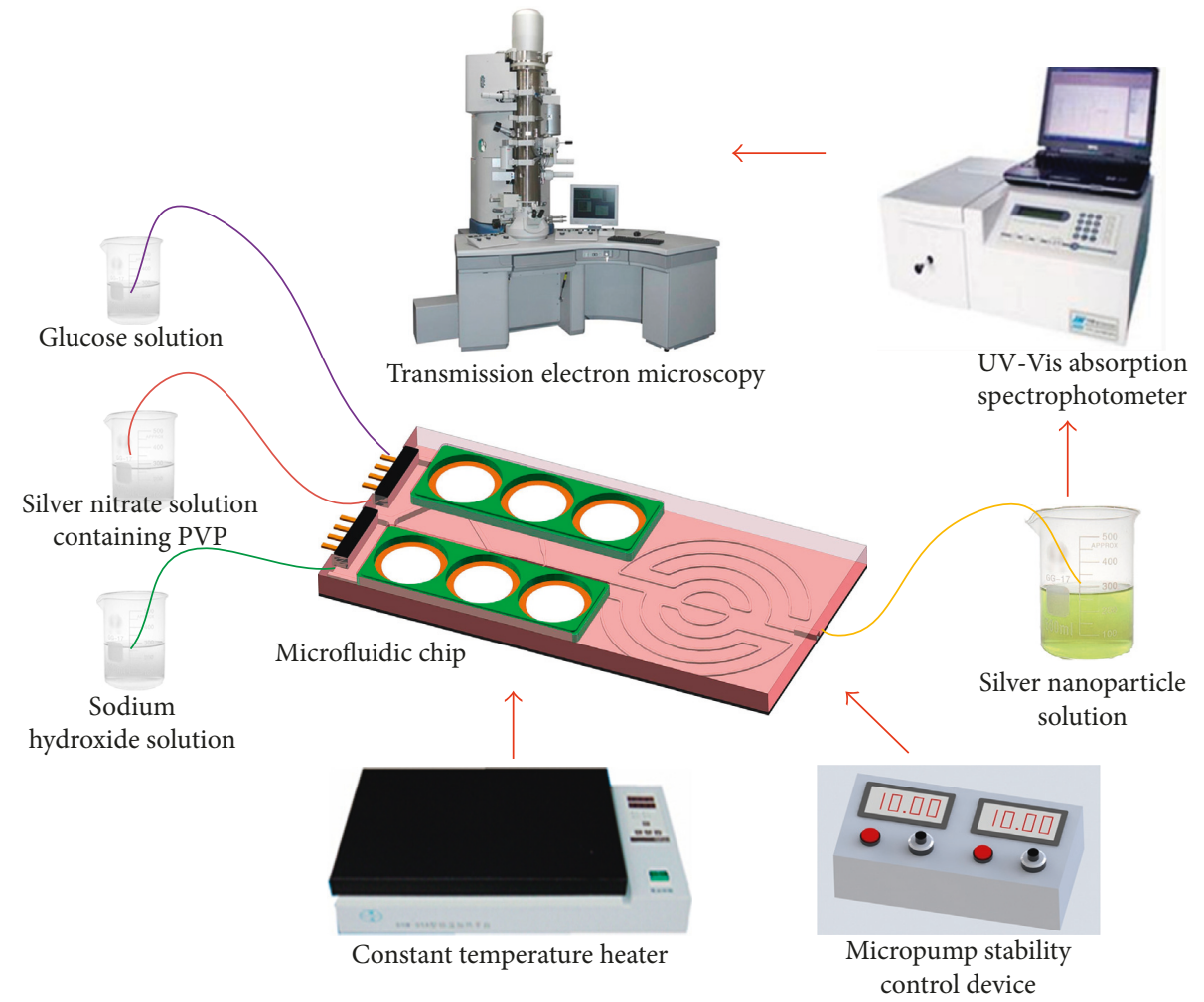

(b)

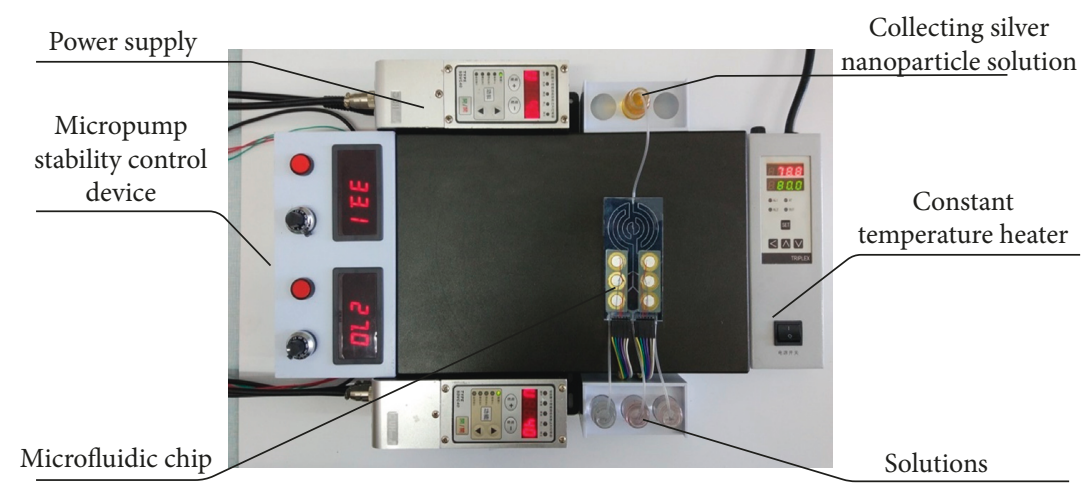

(c)

FIGURE 2: (a) Schematic diagram of the three-phase flow pulsating mixing mechanism. (b) Schematic diagram of experimental scheme. (c) The experimental platform photo. 


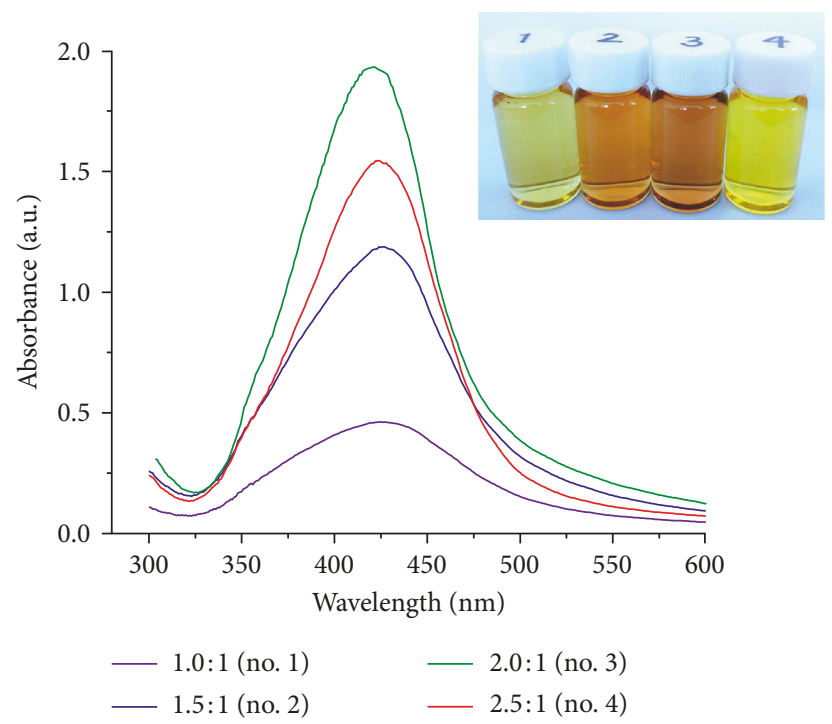

(a)
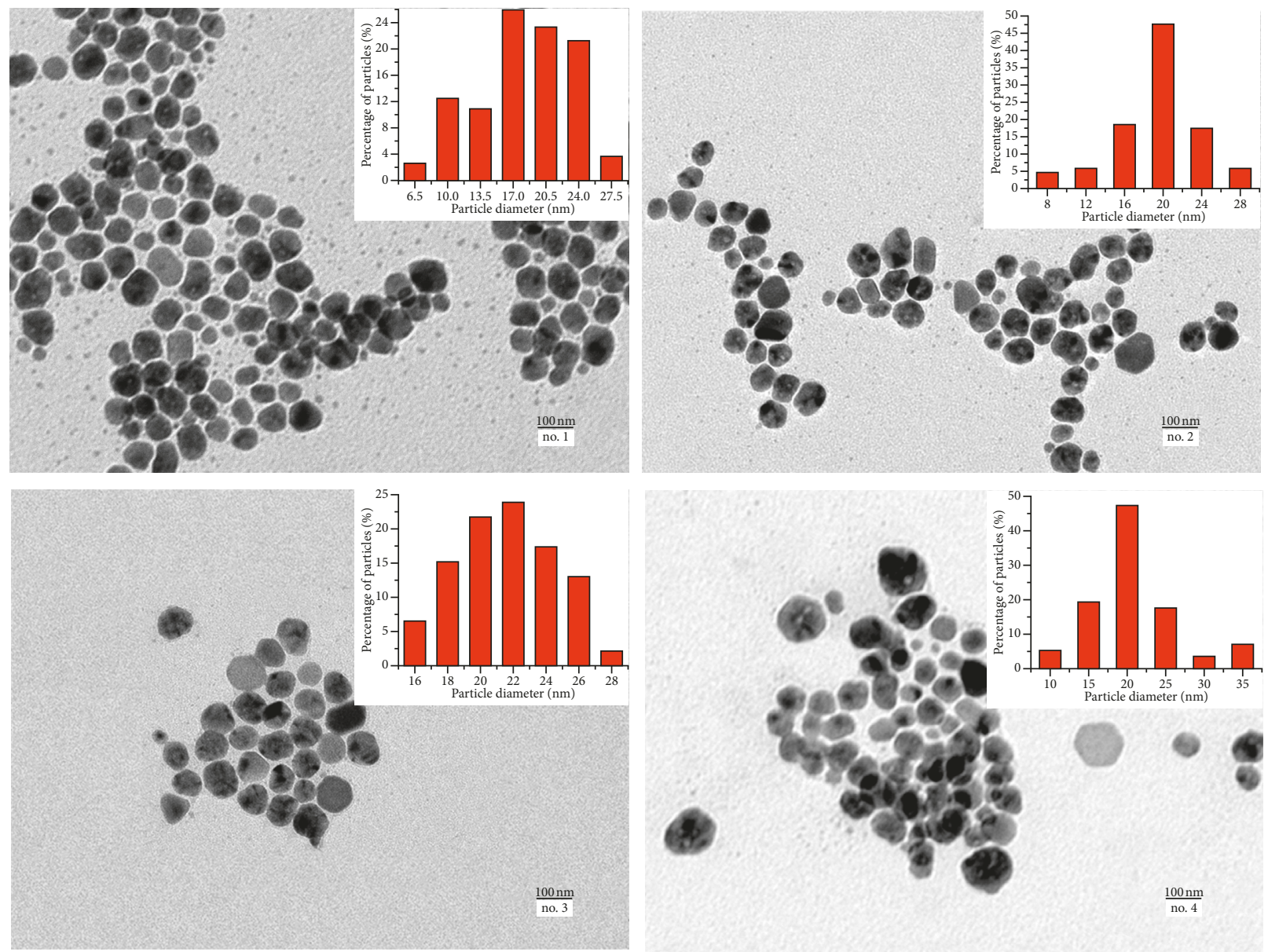

(b)

FIgURE 3: UV-Vis absorption spectra (a) and TEM images (b) of four groups of AgNPs synthesized under different NaOH concentrations.

and synthesis temperature on the particle size, morphology, homogeneity, monodispersity, and yield of AgNPs and then determined the optimum synthesis conditions of AgNPs.

\section{Experiment}

2.1. Reagents. $\mathrm{AgNO}_{3}$ (precursor), $\mathrm{C}_{6} \mathrm{H}_{12} \mathrm{O}_{6}$ (reducing agent), $\mathrm{NaOH}$ (accelerating agent), and PVP (stabilizer) were purchased 
TABle 1: Test results of AgNPs synthesized under different $\mathrm{NaOH}$ concentrations.

\begin{tabular}{lcccc}
\hline Number & $\mathrm{C}_{\mathrm{NaOH}}: \mathrm{C}_{\mathrm{AgNO}_{3}}$ & $\lambda_{\mathrm{m}}(\mathrm{nm})$ & $\alpha_{\mathrm{m}}$ & PWHM $(\mathrm{nm})$ \\
\hline 1 & $1.0: 1$ & 425 & 0.462 & 115.53 \\
2 & $1.5: 1$ & 427 & 1.187 & 99.47 \\
3 & $2.0: 1$ & 421 & 1.943 & 91.63 \\
4 & $2.5: 1$ & 424 & 1.544 & 93.47 \\
\hline
\end{tabular}

from Sinopharm Chemical Reagent Corporation (Shanghai, China). The water used in the experiments was of Milli-Q grade.

2.2. Apparatus. A UV-Vis absorption spectrophotometer (UV-2501 PC, SHIMADZU, Japan) was used to characterize the characteristic absorption spectrum of silver colloid. The size and morphology of synthesized AgNPs were characterized by high-resolution transmission electron microscopy (TEM TECNAI-12, Philips, Holland). The micropumps and microfluidic chip used in experiment were manufactured by mature MEMS process in lab. In addition, a flat panel temperature control heater (BHW-05A Shanghai Broadcom Chemical Technology Co. Ltd.), precision electronic balance (Sartorius Scientific Instrument Co. Ltd.), and PZT actuator control power supply (Nanjing CUH Science \& Technology Co. Ltd.), and so on were used in specific experiment test.

2.3. Fabrication of the Microfluidic Chip. The three-phase flow pulsating mixing microfluidic chip is the core apparatus for the controllable synthesis of AgNPs, which was designed and manufactured by MEMS technology and processes in laboratory. The prototype schematic of the microfluidic chip is shown in Figure 1(a), which consists of two series PZT pumps (pump A and B), one parallel PZT pump, three-phase micromixing channel, growth channel, fluid inlet, and fluid outlet. The key structural parameters of mixing channel have been optimized by the CFD simulation software.

Figure 1(b) is the fabrication flowchart of the microfluidic chip for three-phase flow pulsating mixing. In order to ensure the microfluidic chip having good processing technology on the aspects of chip integration and bonding, and having good working performance in high temperature and corrosive environment, we selected PDMS, silicon, and FR-4 epoxy glass fiber board as material of chip, substrate, and pump body, respectively. The finished prototype has an overall dimension: $100 \mathrm{~mm} \times 50 \mathrm{~mm} \times 5 \mathrm{~mm}$, as shown in Figure 1(c).

2.4. Controllable Synthesis of AgNPs. Based on chemical reduction mechanism, the liquid-phase synthesis method of AgNPs includes three processes, namely, precipitation of silver atoms, nucleation, and growth of crystal nuclei. In the initial stage of reaction of the reducing agent and precursor, the high efficiency mixing is of significant importance. Therefore, it is essential to know how to enhance the mixing characteristic of three-phase microfluid for the controllable synthesis of AgNPs in a microfluidic chip. Figure 2(a) is the schematic diagram of the three-phase flow pulsating mixing mechanism. In the experiment, the working frequency of PZT micropumps is chosen to be $200 \mathrm{~Hz}$, namely, the number of mixing per second reaches 200. Two series PZT micropumps are applied with sine wave electrical signal with a phase difference of 180 degrees. They drive A and B solutions alternately through the micromixing channel in pulsating form. While, for the parallel PZT micropump applied with sine signal, the $\mathrm{C}$ solution is pumped into the mixing channel in a continuous pulse form. Under the reasonable structural parameters and control parameter condition, a thinner pulsating layer can be formed in the micromixing channel. It can effectively increase the contact area and contact opportunity between the solutions, shorten the mixing time, and greatly improve the mixing effect between three solutions $[17,24,25]$. Figure 2(b) is the schematic diagram of experimental scheme, A represents the glucose $\left(\mathrm{C}_{6} \mathrm{H}_{12} \mathrm{O}_{6}\right)$ solution, $\mathrm{C}$ represents the silver nitrate $\left(\mathrm{AgNO}_{3}\right)$ solution containing PVP, and $\mathrm{B}$ represents the sodium hydroxide $(\mathrm{NaOH})$ solution. The above three-phase solutions are mixed intensively and react simultaneously, then entering the annular channel for the growth of crystal nuclei. Finally, the reaction fluid is collected at the outlet and will be inspected after 15 minutes. In the experiment testing, the selfmade stability control device is responsible for the stable output of three-phase flow rate. The temperature control heater is responsible to provide with the appropriate reaction temperature. And the quality of the synthesized AgNPs is mainly analyzed and characterized by the TEM and UV-Vis. The experimental platform photo is shown as Figure 2(c).

\section{Results and Discussion}

3.1. Related Experimental Parameters. During the controllable synthesis of AgNPs using the microfluidic chip and characterization of AgNPs using the related apparatuses, some important experimental parameters are involved. Among them, $\mathrm{C}_{\mathrm{NaOH}}, \mathrm{C}_{\mathrm{AgNO}_{3}}$, and $\mathrm{C}_{\mathrm{C}_{6} \mathrm{H}_{12} \mathrm{O}_{6}}$ represent the concentration of $\mathrm{NaOH}, \mathrm{AgNO}_{3}$, and $\mathrm{C}_{6} \mathrm{H}_{12} \mathrm{O}_{6}$ solution, respectively. The $m_{\mathrm{PVP}}$ and $m_{\mathrm{Ag}}$, respectively, indicate the mass of PVP and the mass of $\mathrm{Ag}$ in $\mathrm{AgNO}_{3}$ solution. $Q$ is the inlet flow rate, and $T$ is the temperature; where $\lambda_{\mathrm{m}}$ is the wavelength of absorption maximum, $\alpha_{\mathrm{m}}$ is the absorption maximum, and PWHM is the peak width at half maximum. Generally, the position of the absorption peak, namely, $\lambda_{\mathrm{m}}$, can reflect the total situation about the size of nanoparticles. Generally, the larger the size of nanoparticles, the greater the value of $\lambda_{\mathrm{m}}$, namely, the peak position shifts to a longer wavelength range [26-28]. Normally, the value of $\alpha_{m}$ is proportional to the concentration of AgNPs' solution. The larger the value of $\alpha_{\mathrm{m}}$, the higher the concentration of the solution and the higher the yield of AgNPs [29]. Besides, PWHM mainly reflects the particle size deviation of AgNPs; in general, the smaller the value of PWHM, the smaller the particle size deviation, the better the uniformity of nanoparticles appearance [30].

3.2. Test Results and Analysis. In the lab, several groups of controllable synthesis of AgNPs were completed using the 


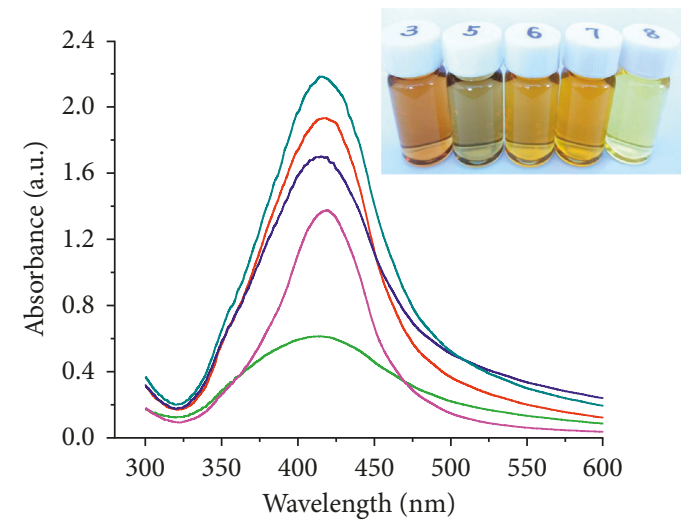

$$
\left.\begin{array}{l}
1: 1(\text { no. } 5) \\
-2: 1(\text { no. } 3) \\
-3: 1(\text { no. 6) }
\end{array} \quad \text { 5:1(no. }\right)
$$

(a)
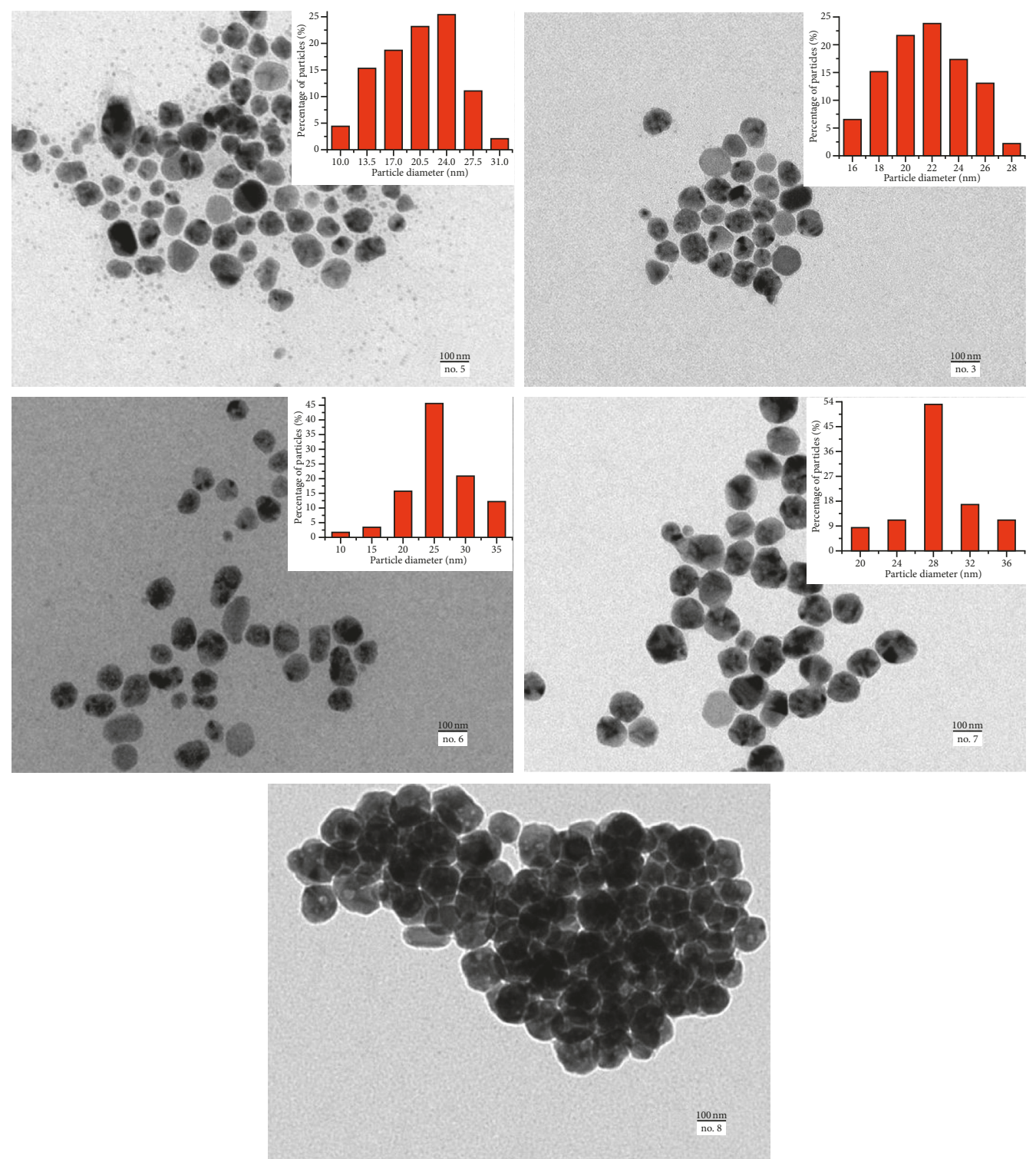

(b)

FIGURE 4: UV-Vis absorption spectra (a) and TEM images (b) of five groups of AgNPs synthesized under different glucose concentrations. 
TABLE 2: Test results of AgNPs synthesized under different glucose concentrations.

\begin{tabular}{lcccc}
\hline Number & $\mathrm{C}_{\mathrm{C}_{6} \mathrm{H}_{12} \mathrm{O}_{6}}: \mathrm{C}_{\mathrm{AgNO}_{3}}$ & $\lambda_{\mathrm{m}}(\mathrm{nm})$ & $\alpha_{\mathrm{m}}$ & PWHM (nm) \\
\hline 5 & $1.0: 1$ & 414 & 0.614 & 118.42 \\
3 & $2.0: 1$ & 421 & 1.943 & 91.63 \\
6 & $3.0: 1$ & 419 & 1.704 & 96.58 \\
7 & $4.0: 1$ & 421 & 2.194 & 91.84 \\
8 & $5.0: 1$ & 419 & 1.379 & 65.22 \\
\hline
\end{tabular}

self-made microfluidic chip, based on the liquid-phase reduction method. Comprehensively analyzing the effects of different experimental factors on the synthesis results of AgNPs, the optimum synthesis conditions of AgNPs were obtained.

3.2.1. Effect of $\mathrm{NaOH}$ Concentration on the Synthesis of AgNPs. Under the different $\mathrm{NaOH}$ concentrations, four groups of synthesis experiments have been carried out. And other experimental conditions were set as follows: the working frequency of PZT micropump was $200 \mathrm{~Hz}$, the initial concentration of $\mathrm{AgNO}_{3}$ solution was $1 \mathrm{mM}$, the temperature was $80^{\circ} \mathrm{C}$, the inlet flow rate $Q$ was set as $3.5 \mathrm{ml} \cdot \mathrm{min}^{-1}$, $\mathrm{C}_{\mathrm{C}_{6} \mathrm{H}_{12} \mathrm{O}_{6}}: \mathrm{C}_{\mathrm{AgNO}_{3}}=2: 1$, and $m_{\mathrm{PVP}}: m_{\mathrm{Ag}}=1.5: 1$. Figure 3 shows the UV-Vis absorption spectra and TEM images of four groups of AgNPs synthesized under different $\mathrm{NaOH}$ concentrations. The detailed test results are shown in Table 1.

Analyzing the UV-Vis absorption spectra of Figure 3(a) and tests data in Table 1, we can find that the maximum absorption wavelengths of four groups of sample solutions are in the range of $400 \sim 430 \mathrm{~nm}$, which all accord with the typical optical characteristics of AgNP colloidal system. From the approximately same value of $\lambda_{\mathrm{m}}$ of four groups of samples, it can be seen that the concentration of $\mathrm{NaOH}$ has little influence on the particle size of AgNPs. Observing the change of the value of $\alpha_{\mathrm{m}}$, we can see that with the increasing of $\mathrm{NaOH}$ concentration, the maximum absorbance of AgNP sol increases first and then decreases. Among them, sample no. 3 has the largest value of the absorption maximum $\alpha_{\mathrm{m}}$, 1.943. It also indicates that the concentration (i.e., yield) of AgNPs similarly increases first and then decreases. The changes of test data directly coincide with the colour changes of samples. Accordingly, it first turns darker and then becomes shallower, and sample no. 3 has the darkest colour. Analyzing the values of PWHM, we can find that sample no. 1 has the largest value, while no. 3 has the smallest one. It means that the synthesized AgNPs of no. 3 has the smallest deviation of particle size and more uniform particle distribution. Thus, the synthesis conditions of sample no. 3 are relatively better. The TEM photographs of Figure 3(b) show that the AgNP morphologies of other three groups are approximately spherical and monodisperse, with the exception of no. 4. Sample no. 4 shows the undesirable particle aggregation and poor morphology. For the reason of aggregation, we think it may be the excessive $\mathrm{NaOH}$ concentration $\left(\mathrm{C}_{\mathrm{NaOH}}: \mathrm{C}_{\mathrm{AgNO}_{3}}=2.5: 1\right)$ which gives rising to a rapid increase of the silver atom concentration in solution. While the concentration of reduced silver atoms is too large, the probability of nuclei collision will increase during the formation process of ArgentCrystal. The rapid aggregation of nuclei will lead to the formation of irregular nanostructures and even cause partial agglomeration of nanoparticles. Hence, the synthesis effect under this condition is not ideal. In addition, by analyzing the spectrogram of Figure 3(a), we can also find that the maximum absorbance does not maintain a growth trend with the increase of $\mathrm{NaOH}$ concentration. This phenomenon still may be due to the higher $\mathrm{NaOH}$ concentration, which results in the precipitation reaction of silver hydroxide because of the remaining excessive $\mathrm{OH}^{-}$and $\mathrm{Ag}^{+}$in reaction solution.

Comprehensively considering the test results and discussion, it can be found that the concentration of $\mathrm{NaOH}$ solution has a great influence on the yield, morphology, monodispersity, and particle size uniformity of the synthesized AgNPs. So, as the important accelerating agent, a suitable optimum $\mathrm{NaOH}$ concentration is required. In the actual experiment, when $\mathrm{C}_{\mathrm{NaOH}}: \mathrm{C}_{\mathrm{AgNO}_{3}}=2: 1$, the spherical AgNPs with higher concentration, smaller particle size deviation, and better dispersion were synthesized.

3.2.2. Effect of Glucose Concentration on the Synthesis of $A g N P s$. In order to study the effect of $\mathrm{C}_{6} \mathrm{H}_{12} \mathrm{O}_{6}$ concentration on the synthesis of AgNPs, five groups of synthesis experiments were carried out using the self-made microfluidic chip under different concentrations of glucose $\left(\mathrm{C}_{\mathrm{C}_{6} \mathrm{H}_{12} \mathrm{O}_{6}}\right)$. The basic experimental conditions are the same as the research on effect of $\mathrm{NaOH}$ concentration, except of a concentration ratio $\left(\mathrm{C}_{\mathrm{NaOH}}: \mathrm{C}_{\mathrm{AgNO}_{3}}=2: 1\right)$. The UV-Vis absorption spectra and TEM images of five groups of AgNPs synthesized under different glucose concentrations are shown in Figure 4. The detailed test results are listed in Table 2.

Analyzing the UV-Vis absorption spectra of Figure 4(a) and tests data in Table 2, we can find that the maximum absorption wavelengths of five groups of sample solutions are in the range of $410 \sim 430 \mathrm{~nm}$, and when $\mathrm{C}_{\mathrm{C}_{6} \mathrm{H}_{12} \mathrm{O}_{6}}: \mathrm{C}_{\mathrm{AgNO}_{3}}=$ $1: 1$, the maximum absorption wavelengths $\lambda_{\mathrm{m}}$ has a little small value. After the concentration ratio of glucose to precursor exceeds 2 , the maximum absorption wavelength of the sample shows obvious red shift, but the value of $\lambda_{\mathrm{m}}$ changes little, which means the synthesized nanoparticle sizes are less affected. Comparing the changes in the maximum absorption peaks (the values of $\alpha_{\mathrm{m}}$ ), it can be concluded that with the increasing of glucose concentration, the maximum absorbance of AgNP sol increases first and then decreases. Among them, sample no. 7 has the largest value of the absorption maximum $\alpha_{\mathrm{m}}$ (2.194) which means sample no. 7 has the highest yield of AgNPs. Based on the values of PWHM, sample no. 8 will have the smallest deviation of nanoparticle size and then followed by no. 3 and no. 7 which have approximately the same deviation in nanoparticle size. But comprehensively considering the TEM images of Figure 4(b), we will find that AgNPs of sample no. 8 have poor monodispersity and morphology. For sample no. 8, not only the maximum absorbance is lower, but the more severe agglomeration occurs. As for the possible reasons, we believe that when the glucose concentration of reaction solution is 


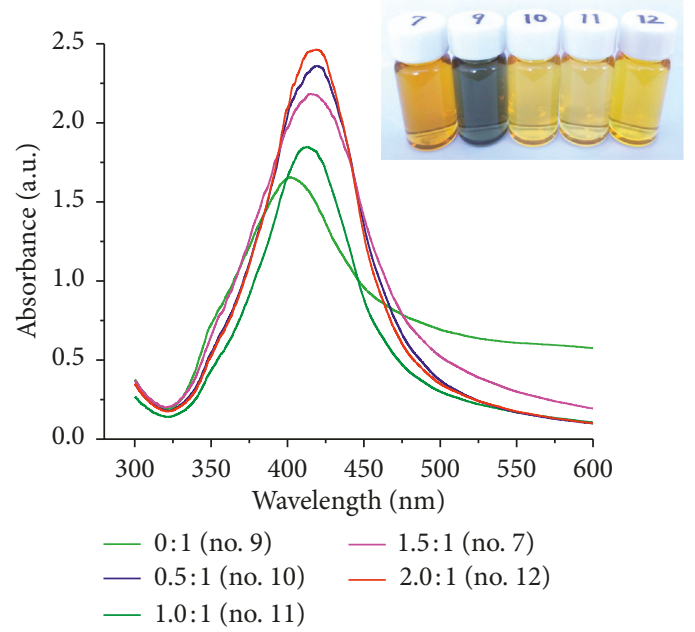

(a)
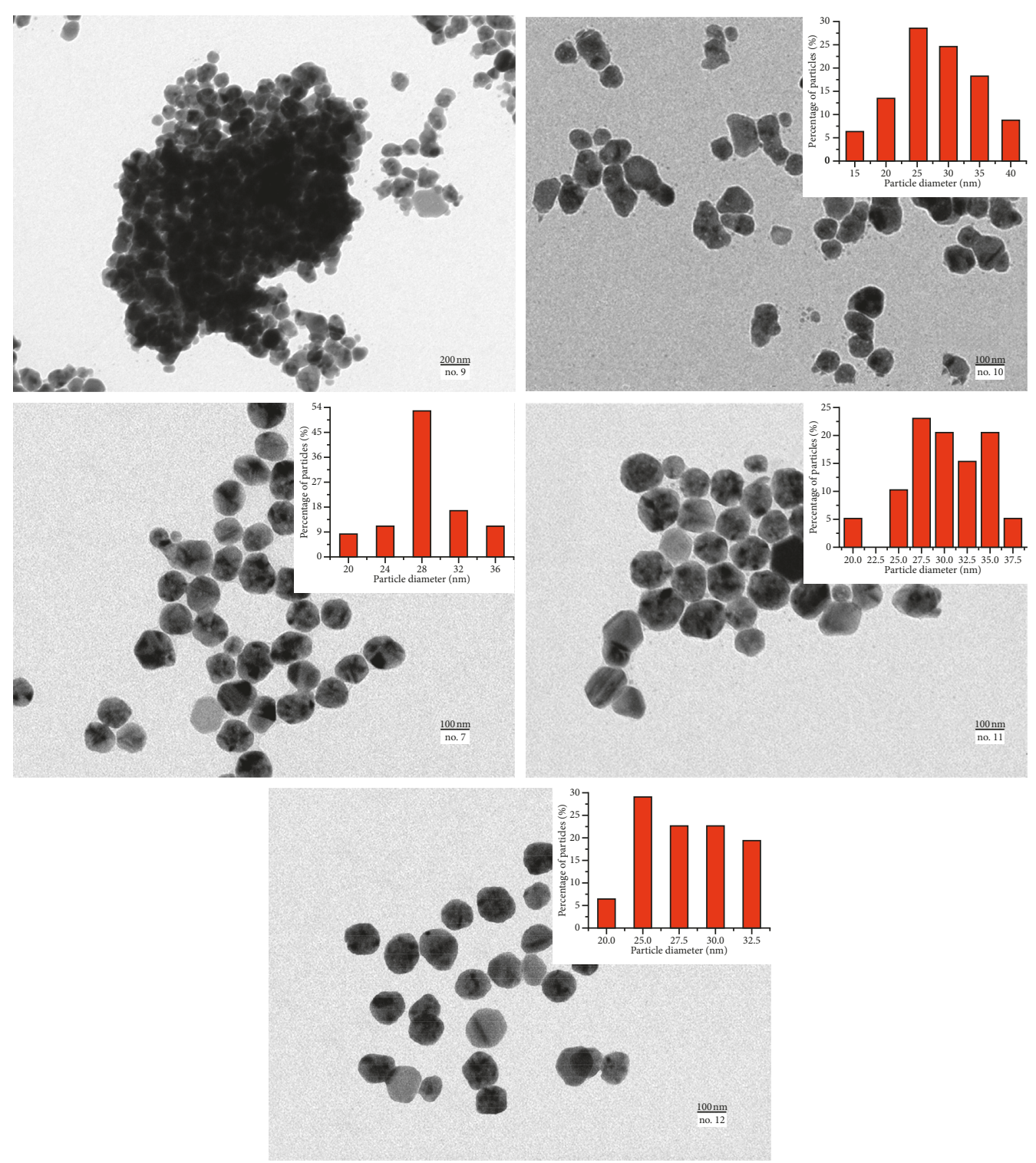

(b)

FIgURE 5: UV-Vis absorption spectra (a) and TEM images (b) of five groups of AgNPs synthesized under different PVP dosages. 
too large, the rate of reduction of silver atoms is too fast, which will give rise to the increase of internuclear collision probability of ArgentCrystal and the formation of island agglomerated particles. And it is due to the serious aggregation of AgNPs leading to the decrease in the concentration and the maximum absorbance of AgNPs.

In summary, the glucose concentration affects the synthesis of AgNPs a lot, especially has a great influence on the yield, morphology, and monodispersity of AgNPs. Among the five groups of synthesis experiments launched in lab, samples of no. 3 and no. 7 all have a better synthesis effect. But in view of higher yield of AgNPs in no. 7, the synthesis conditions of sample no. 7 were finally selected as the best synthesis conditions, namely, the optimal concentration of $\mathrm{C}_{6} \mathrm{H}_{12} \mathrm{O}_{6}$ solution in the experiment is $4 \mathrm{mM}$ $\left(\mathrm{C}_{\mathrm{C}_{6} \mathrm{H}_{12} \mathrm{O}_{6}}: \mathrm{C}_{\mathrm{AgNO}_{3}}=4: 1\right)$.

3.2.3. Effect of PVP Dosage on the Synthesis of AgNPs. In order to study the effect of the PVP dosage on the synthesis of AgNPs, the related synthesis experiments were carried out. The basic experiment conditions are the same as that of above Section 3.2.1 (among them, $\mathrm{C}_{\mathrm{NaOH}}: \mathrm{C}_{\mathrm{AgNO}_{3}}=2: 1$ and $\mathrm{C}_{\mathrm{C}_{6} \mathrm{H}_{12} \mathrm{O}_{6}}: \mathrm{C}_{\mathrm{AgNO}_{3}}=4: 1$ ). According to the different amount of PVP used in the experiment, the synthesis experiments were designed and divided into five groups. Through relevant experiment testing, the UV-Vis absorption spectra and TEM images of five groups of AgNPs synthesized based on different PVP dosages as shown in Figure 5 were obtained. The detailed test results are listed in Table 3.

Analyzing the changes of the maximum absorption wavelengths $\lambda_{\mathrm{m}}$, we can observe that samples no. 9 and no. 10 show an obvious blue shift, while the maximum absorption wavelengths of other samples vary little or almost no change. It shows that with the increase of PVP dosage, the particle size of AgNPs shows a rising trend at the initial stage. But, when the amount of PVP increases to a certain value, it has little effect on the particle size of synthesized nanoparticles.

The changes of test data $\alpha_{\mathrm{m}}$ also show that the effect of PVP addition on the synthesis of AgNPs is obvious. As the amount of PVP increases, the maximum absorption peaks $\alpha_{\mathrm{m}}$ from the initial value 1.659 increases to 2.165 . It can be seen that whether PVP is added or not has a great influence on the yield of AgNPs. However, when the mass ratio of PVP to $\mathrm{Ag}$ is more than 1 , namely, $m_{\mathrm{PVP}}: m_{\mathrm{Ag}} \geq 1$, the amount of PVP has little effect on the yield of AgNPs. Similarly, the value of PWHM also shows a similar variation trend.

Through further observation of the sample photos and TEM images in Figures 5(a) and 5(b), it can be found that sample no. 9 becomes turbid, the synthesized nanoparticles produce serious aggregation, at the same time, the morphology and monodispersity of nanoparticles are poor, too. After a small amount of PVP $\left(m_{\mathrm{PVP}}: m_{\mathrm{Ag}}=0.5: 1\right)$ is added, no obvious precipitation occurs in the sample solution. Although the morphology and monodispersity of synthesized nanoparticles have been improved, the overall situation is still relatively poor, and some nanoparticles are still agglomerated. Only when the amount of PVP in solution
TABle 3: Test results of AgNPs synthesized under different PVP dosages.

\begin{tabular}{lcccc}
\hline Number & $m_{\mathrm{PVP}}: m_{\mathrm{Ag}}$ & $\lambda_{\mathrm{m}}(\mathrm{nm})$ & $\alpha_{\mathrm{m}}$ & PWHM $(\mathrm{nm})$ \\
\hline 9 & $0: 1($ no PVP) & 402 & 1.659 & 114.47 \\
10 & $0.5: 1$ & 413 & 1.848 & 87.11 \\
11 & $1: 1$ & 419 & 2.181 & 90.89 \\
7 & $1.5: 1$ & 421 & 2.194 & 91.84 \\
12 & $2: 1$ & 419 & 2.165 & 91.05 \\
\hline
\end{tabular}

exceeds a certain amount (e.g., $m_{\mathrm{PVP}}: m_{\mathrm{Ag}}=1: 1, m_{\mathrm{PVP}}$ : $m_{\mathrm{Ag}}=1.5: 1$, and $m_{\mathrm{PVP}}: m_{\mathrm{Ag}}=2: 1$ ), the aggregation phenomenon of synthesized AgNPs no longer occurs, and the morphology and monodispersity of nanoparticles become better.

Comprehensively analyzing the test results, we find that the amount of PVP has a great influence on the synthesis of AgNPs, especially on the morphology and monodisperse properties of the synthesized nanoparticles. As for the action mechanism, we think that, as a stabilizer, PVP plays a role of surface protective agent in the synthesis of AgNPs. When no PVP is added, or the amount of PVP is less, the silver crystal nuclei formed in the solution cannot be completely encapsulated, and which directly leads to the results that most of synthesized nanoparticles cannot grow into a normal spherical or spherical-like shape. Furthermore, since the nanoparticles are incompletely wrapped, the smaller electrostatic repulsion forces between nanoparticles give rise to the partial agglomeration. While the amount of PVP is sufficient, the silver crystal nuclei fully coated by PVP are more likely to grow into spherical or spherical-like nanoparticles. At the same time, as the amide strong polar groups of PVP are negatively charged, this improves the electrostatic repulsion between nanoparticles. Hence, it is beneficial to synthesize the spherical or spherical-like AgNPs with good dispersibility.

Therefore, it is essential to add proper amount of PVP in order to synthesize AgNPs with regular morphology and good dispersibility.

\subsubsection{Effect of Inlet Flow Rate of Microfluidic Chip on the} Synthesis of AgNPs. For the pulsating mixing microfluidic chip actuated by PZT, the working frequency and the inlet flow rate of mixing channels are very important and critical operating parameters that affect the working performance of the chip. No matter for two-phase or three-phase flow mixing, once the working frequency is determined, there will be an optimal flow rate to match it. In order to investigate the influence of the inlet flow rate on the synthesis of AgNPs, the working frequency was selected as $200 \mathrm{~Hz}$ [17], and the related experiments based on four groups of inlet flow rates were carried out. The test of the basic experimental conditions was as follows: the initial concentration of silver nitrate solution is $1 \mathrm{mM}$, the experimental temperature is $80^{\circ} \mathrm{C}, \mathrm{C}_{\mathrm{NaOH}}: \mathrm{C}_{\mathrm{AgNO}_{3}}=2: 1, \mathrm{C}_{\mathrm{C}_{6} \mathrm{H}_{12} \mathrm{O}_{6}}: \mathrm{C}_{\mathrm{AgNO}_{3}}=4: 1$, and $m_{\mathrm{PVP}}: m_{\mathrm{Ag}}=1.5: 1$. Through series of experimental tests, the UV-Vis absorption spectra and TEM images of four groups of AgNPs synthesized based on different inlet flow rates as 


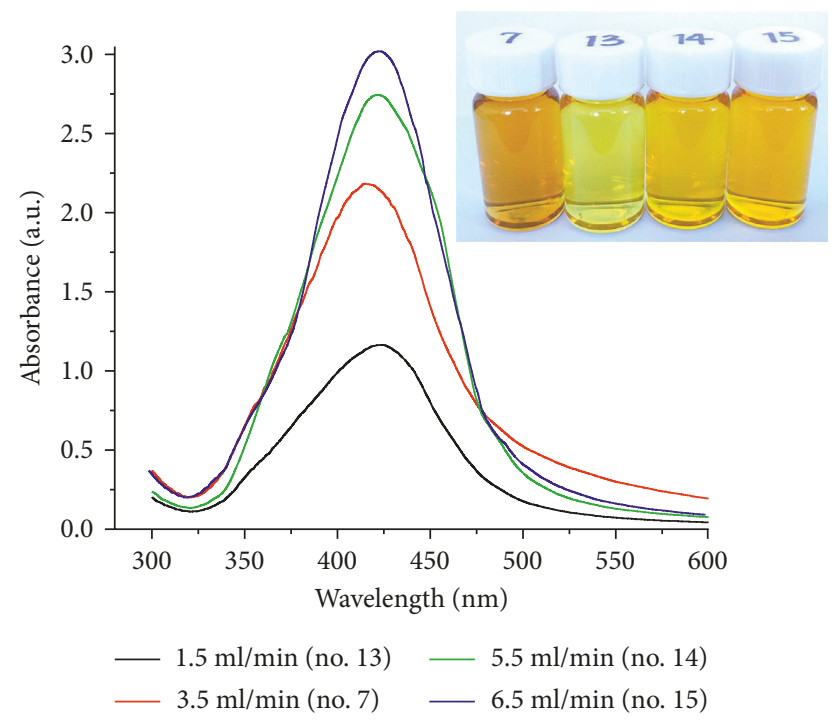

(a)
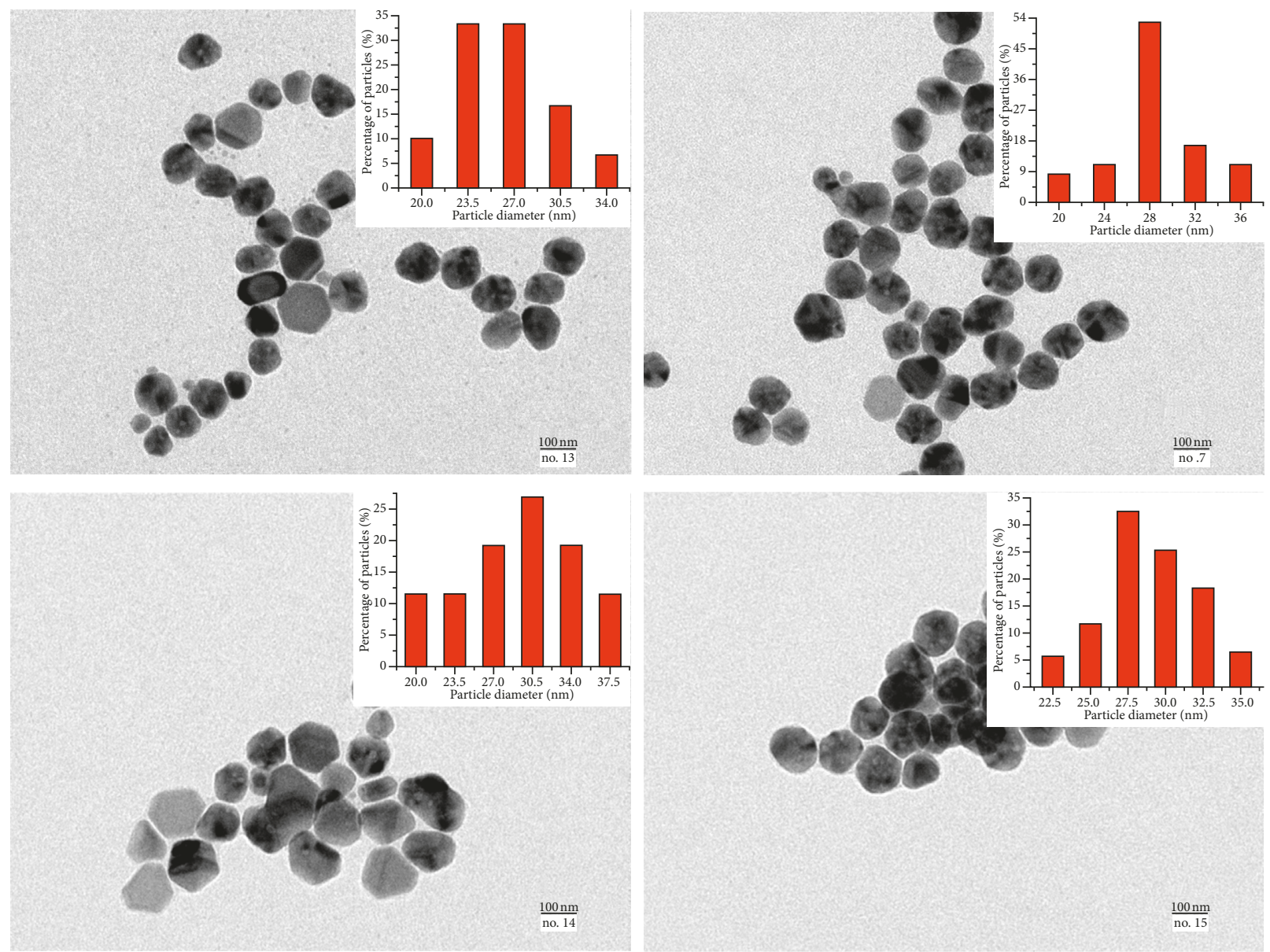

(b)

FiguRE 6: UV-Vis absorption spectra (a) and TEM images (b) of four groups of AgNPs synthesized under different inlet flow rates.

shown in Figure 6 were obtained, and the detailed test results are listed in Table 4.

Analyzing the UV-Vis absorption spectra and the related data, we find that when the inlet flow rate is $3.5 \mathrm{ml} \cdot \mathrm{min}^{-1}$, the synthesized nanoparticles had a smaller mean particle size. While the flow rate is $6.5 \mathrm{ml} \cdot \mathrm{min}^{-1}$, the size of the synthesized nanoparticles is a little large. Observing the data of $\alpha_{\mathrm{m}}$, we can conclude that the yield of AgNPs increases with the 
TABLE 4: Test results of AgNPs synthesized under different inlet flow rates.

\begin{tabular}{lcccc}
\hline Number & $Q\left(\mathrm{ml} \cdot \mathrm{min}^{-1}\right)$ & $\lambda_{\mathrm{m}}(\mathrm{nm})$ & $\alpha_{\mathrm{m}}$ & PWHM $(\mathrm{nm})$ \\
\hline 13 & 1.5 & 424 & 1.165 & 88.58 \\
7 & 3.5 & 421 & 2.194 & 91.84 \\
14 & 5.5 & 430 & 2.742 & 93.16 \\
15 & 6.5 & 426 & 3.020 & 91.39 \\
\hline
\end{tabular}

increase of the inlet flow rate. From the PWHM point of view, we can see that the values of half peak width of four samples first increase and then decrease. But, in view of the overall values of PWHM, the size uniformity of the synthesized AgNPs is better relatively. Comparing the TEM photographs of the synthesized AgNPs, we find that when the flow rate is $5.5 \mathrm{ml} \cdot \mathrm{min}^{-1}$, the morphology of synthesized nanoparticles is relatively poor; while the flow rate reaches $6.5 \mathrm{ml} \cdot \mathrm{min}^{-1}$, part of nanoparticles produce agglomeration. For the occurrence of agglomeration, we think that this may be due to the excessive flow speed. Although the flow rate is large, the comprehensive mixing efficiency is not the best. Furthermore, the excessive flow speed directly leads to the increase of the collision probability between the nuclei of ArgentCrystal, which in turn makes it easy to form irregular nanostructures, even agglomerate.

In summary, the inlet flow rate of microfluidic chip is an important factor for the controllable synthesis of AgNPs, which affects the size, yield, morphology, and monodispersity of the synthesized nanoparticles. With the increase of the inlet flow rate, the AgNP yield gradually increases, but the high flow rate will lead to poor morphology of synthesized nanoparticles and even aggregation of some nanoparticles. Moreover, for the micromixing based on the pulsating mixing mechanism, once the working frequency is determined, there will be an optimal inlet flow rate to match it. Comprehensively analyzing and comparing the above experimental results, we conclude that when the flow rate is $3.5 \mathrm{ml} \cdot \mathrm{min}^{-1}$, a spherical AgNP with relatively high concentration, good morphology, and good monodispersity has been synthesized. Therefore, the optimum inlet flow rate is $3.5 \mathrm{ml} \cdot \mathrm{min}^{-1}$, when the working frequency is $200 \mathrm{~Hz}$.

3.2.5. Effect of Temperature on the Synthesis of AgNPs. In order to study the effect of temperature on the synthesis of AgNPs, five groups of synthesis experiments at different temperatures were designed and carried out. The basic experiment conditions, such as the working frequency of PZT micropump, the initial concentration of $\mathrm{AgNO}_{3}$ solution, the inlet flow rate, and the PVP dosage, are the same as those in Section 3.2.1. In addition, the concentration parameters of $\mathrm{C}_{6} \mathrm{H}_{12} \mathrm{O}_{6}$ and $\mathrm{NaOH}$ were $\mathrm{C}_{\mathrm{C}_{6} \mathrm{H}_{12} \mathrm{O}_{6}}: \mathrm{C}_{\mathrm{AgNO}_{3}}=$ $4: 1$, and $\mathrm{C}_{\mathrm{NaOH}}: \mathrm{C}_{\mathrm{AgNO}_{3}}=2: 1$, respectively. The UV-Vis absorption spectra and TEM images of five groups of AgNPs synthesized based on different temperatures as shown in Figure 7 were obtained. The detailed test results are listed in Table 5.
Analyzing the UV-Vis absorption spectra and the related data, we will find that although the test data are quite different, the maximum absorption wavelengths all change in the range of 400 430 nm, which well accord with specific optical characteristics of spherical AgNP sol. The positions of data $\lambda_{\mathrm{m}}$ show that with the increase of temperature, the maximum absorption wavelength of AgNPs appears to be red shifted first and then blue shifted. The results show that the size of AgNPs increases first and then decreases with the increase of temperature. While the test data $\alpha_{\mathrm{m}}$ show that the maximum absorbance increases first and then decreases sharply with the increase of temperature, and the maximum absorbance reaches maximum when the temperature is $60^{\circ} \mathrm{C}$ and $80^{\circ} \mathrm{C}$. When the temperature is set at $100^{\circ} \mathrm{C}$ and $120^{\circ} \mathrm{C}$, the maximum absorbance $\alpha_{\mathrm{m}}$ is lower, and the synthesis effect is relatively poorer, which indicates that the synthesis temperature of AgNPs should not be too high when synthesized using the microfluidic chip. Moreover, the TEM photos of Figure 7(b) also show that the size uniformity and monodispersity of the synthesized AgNPs are relatively poorer, when the temperature is $100^{\circ} \mathrm{C}$ and $120^{\circ} \mathrm{C}$. The most likely cause is that the reaction rate of synthesis process of AgNPs increases too fast, with the increase of temperature. Meanwhile, as the collision probability of silver atom increases, the growth rate of crystal nuclei will exceed that of silver atoms. Therefore, the size of synthesized AgNPs is not uniform, the size deviation of AgNPs is large, and some nanoparticles are even aggregated.

In summary, too high or too low temperature is not conducive to the synthesis of AgNPs. In our synthesis experiments, when the temperature is set at $60^{\circ} \mathrm{C}$ and $80^{\circ} \mathrm{C}$, the particle size, yield, morphology, monodispersity, and particle size uniformity of synthesized AgNPs are relatively good. After comprehensive comparison and analysis, we select $80^{\circ} \mathrm{C}$ as the optimum temperature of AgNPs' synthesis.

3.3. Size and Deviation of AgNPs Synthesized under Optimum Conditions. The AgNPs' synthesis using the liquid-phase reduction method has many influencing factors. In this paper, a self-made three-phase flow pulsating mixing microfluidic chip was presented. Using the microfluidic chip, a series of controllable synthesis experiments of AgNPs had been designed and carried out under various factors. By comparing and analyzing the test results, we obtained the optimal synthesis conditions under limited experimental conditions. The specific conditions are as follows: the working frequency of PZT micropump is $200 \mathrm{~Hz}$, the initial concentration of $\mathrm{AgNO}_{3}$ solution is $1 \mathrm{mM}$, the temperature is $80^{\circ} \mathrm{C}$, the inlet flow rate $Q$ is $3.5 \mathrm{ml} \cdot \mathrm{min}^{-1}, \mathrm{C}_{\mathrm{NaOH}}: \mathrm{C}_{\mathrm{AgNO}_{3}}=2: 1$,

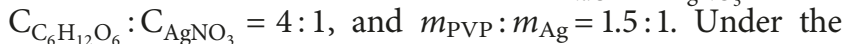
above conditions, AgNPs with uniform size, good morphology, and monodispersity have been synthesized. Moreover, the size and deviation of synthesized AgNPs are about $29.11 \pm 3.98 \mathrm{~nm}$. The TEM image and histogram of particle size distribution of synthesized AgNPs are shown in Figure 8. 


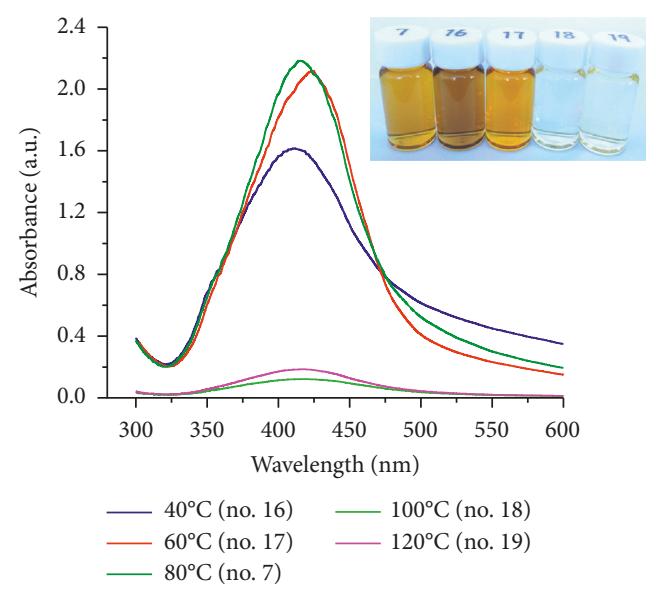

(a)
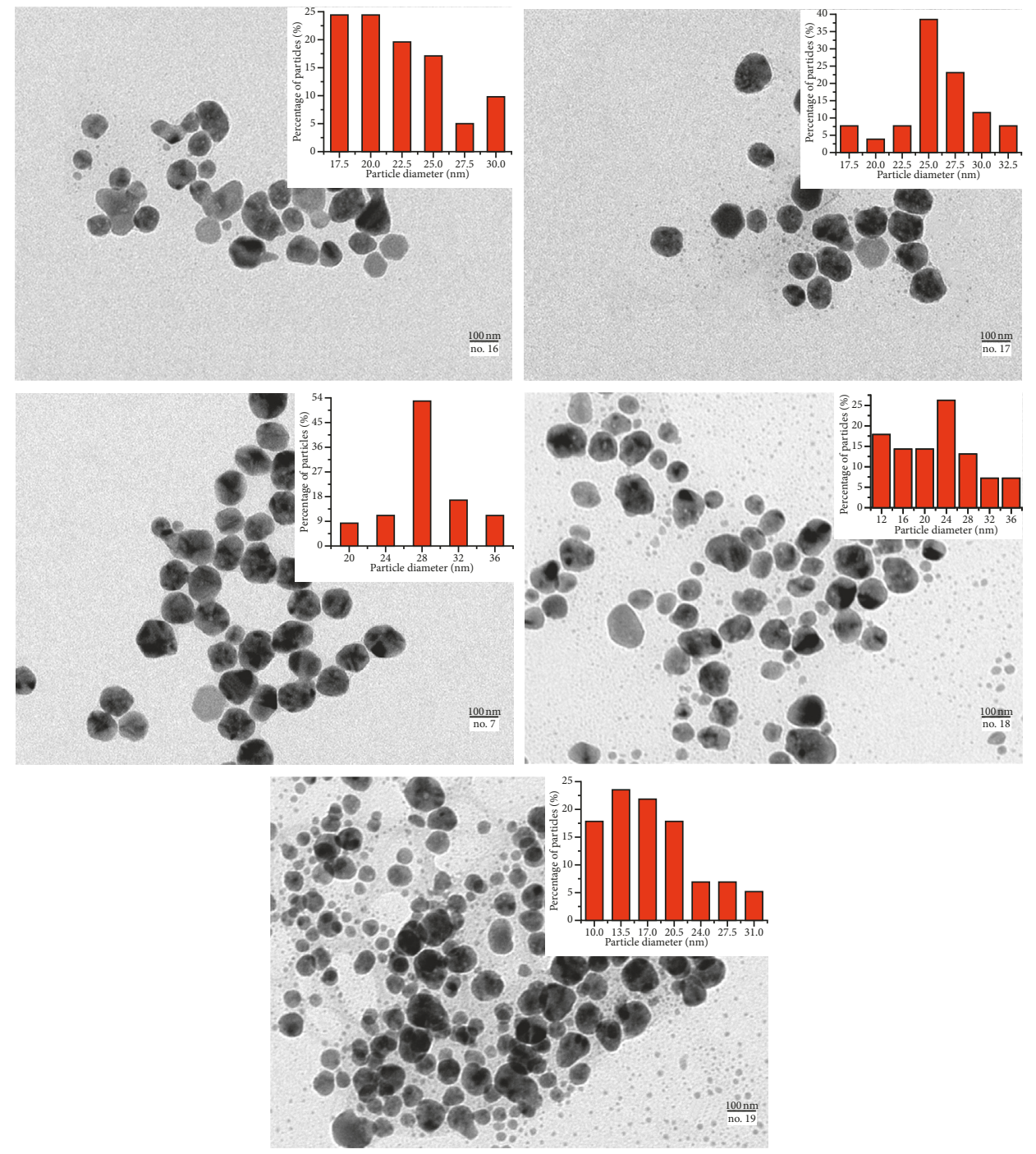

(b)

FIgURe 7: UV-Vis absorption spectra (a) and TEM images (b) of five groups of AgNPs synthesized under different temperatures. 
TABle 5: Test results of AgNPs synthesized under different temperatures.

\begin{tabular}{lcccc}
\hline Number & $\mathrm{T}\left({ }^{\circ} \mathrm{C}\right)$ & $\lambda_{\mathrm{m}}(\mathrm{nm})$ & $\alpha_{\mathrm{m}}$ & \\
\hline 16 & 40 & 411 & 1.167 & PWHM $(\mathrm{nm})$ \\
17 & 60 & 422 & 2.123 & 93.95 \\
7 & 80 & 421 & 2.194 & 91.84 \\
18 & 100 & 416 & 0.122 & 93.68 \\
19 & 120 & 417 & 0.185 & 82.69 \\
\hline
\end{tabular}

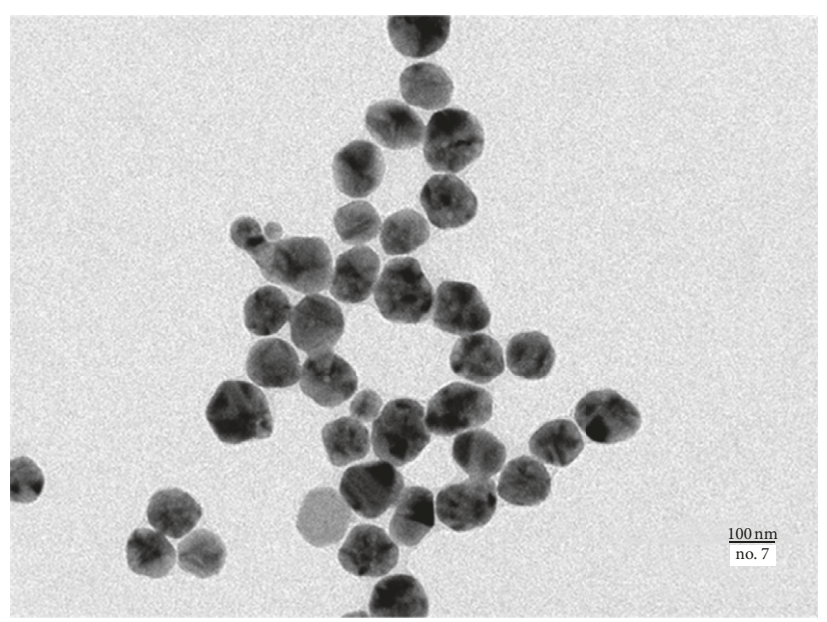

(a)

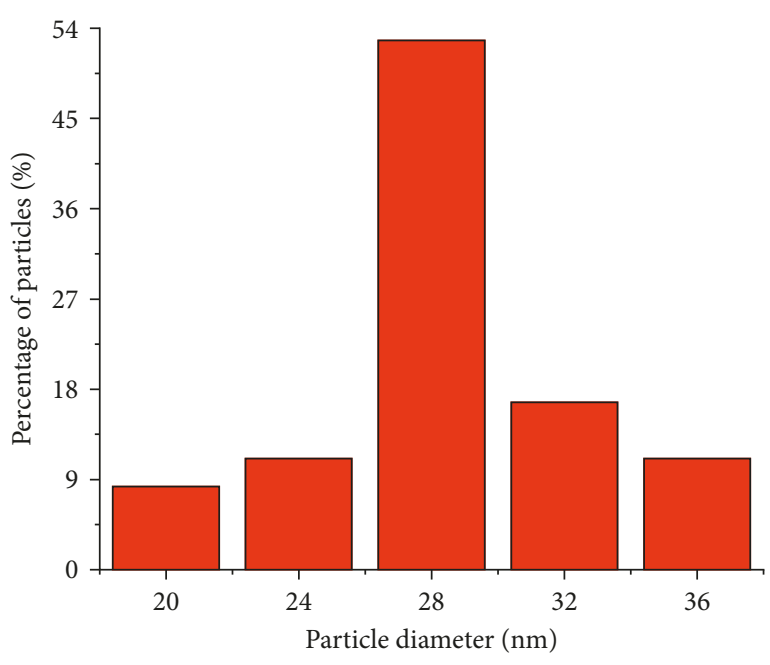

(b)

FIgUre 8: The TEM image (a) and histogram of particle size distribution (b) of synthesized AgNPs.

\section{Conclusion}

Based on the reduction of silver nitrate with glucose, the controllable synthesis experiments of AgNPs were carried out by using a three-phase flow pulsating mixing microfluidic chip. Through investigating and exploring the influence of different factors on the synthesis of AgNPs, the optimum synthesis conditions of AgNPs were obtained, and the following conclusions were drawn:

(1) It is an efficient and feasible experimental method to develop controllable synthesis experiments of AgNPs under multifactors by using the three-phase pulsating mixing microfluidic chip. This method can be extended to many research fields, such as the controllable synthesis of other nanoparticles and the control of complex chemical reactions.

(2) When AgNPs are synthesized by the microfluidic chip, the influence of different synthesis conditions on AgNPs is quite different. $\mathrm{NaOH}$ concentration, PVP dosage, microfluidic chip entrance flow, $\mathrm{C}_{6} \mathrm{H}_{12} \mathrm{O}_{6}$ concentration, and reaction temperature have great influence on the aspects of the particle size, yield, morphology, dispersibility, and uniformity of the particle size. Under the limited experimental conditions, the above experimental parameters all have their own optimal value, and too high or too low is not conducive to the controllable synthesis of AgNPs.

(3) When the working frequency of the PZT micropump is set as $200 \mathrm{~Hz}$, the initial concentration of $\mathrm{AgNO}_{3}$ solution is $1 \mathrm{mM}$, the temperature is $80^{\circ} \mathrm{C}$, the inlet flow rate $Q$ is set as $3.5 \mathrm{ml} \cdot \mathrm{min}^{-1}$, $\mathrm{C}_{\mathrm{NaOH}}: \mathrm{C}_{\mathrm{AgNO}_{3}}=2: 1, \mathrm{C}_{\mathrm{C}_{6} \mathrm{H}_{12} \mathrm{O}_{6}}: \mathrm{C}_{\mathrm{AgNO}_{3}}=4: 1, m_{\mathrm{PVP}}$ : $m_{\mathrm{Ag}}=1.5: 1$, the AgNPs with uniform size, and good morphology and monodispersity have been synthesized. The size and deviation of synthesized AgNPs are about $29.11 \pm 3.98 \mathrm{~nm}$.

\section{Conflicts of Interest}

The authors declare that they have no conflicts of interest.

\section{Acknowledgments}

This research is supported and funded by the National Natural Science Foundation Projects (no. 51375207) from Ministry of Science and Technology of the People's Republic of China and the Jilin Province Natural Science Foundation Projects (no. 20170101136JC). The authors thank the Chain Drive Research Institution of Jilin University for the energetic support and help in the aspect of microdevice fabrication and electronic control unit (R\&D). 


\section{References}

[1] H.-J. Li, A.-Q. Zhang, L. Sui, D.-J. Qian, and M. Chen, "Hyaluronan/Tween 80-assisted synthesis of silver nanoparticles for biological application," Journal of Nanoparticle Research, vol. 17, no. 2, p. 111, 2015.

[2] Y. Lu, Y. Mei, M. Drechsler, and M. Ballauff, "Thermosensitive core-shell particles as carriers for Ag nanoparticles: modulating the catalytic activity by a phase transition in networks," Angewandte Chemie, vol. 45, no. 5, pp. 813-816, 2006.

[3] A. C. Patel, S. Li, C. Wang, W. J. Zhang, and Y. Wei, "Electrospinning of porous silica nanofibers containing silver nanoparticles for catalytic applications," Chemistry of Materials, vol. 19, no. 6, pp. 1231-1238, 2007.

[4] S. Mishra and H. B. Singh, "Biosynthesized silver nanoparticles as a nanoweapon against phytopathogens: exploring their scope and potential in agriculture," Applied Microbiology and Biotechnology, vol. 99, no. 3, pp. 1097-1107, 2015.

[5] Y.-C. Tsai, T.-M. Wu, P.-C. Hsu, and Y.-W. Lin, "Silver nanoparticles in multiwalled carbon nanotube-Nafion for surface-enhanced Raman scattering chemical sensor," Sensors and Actuators B: Chemical, vol. 138, no. 1, pp. 5-8, 2009.

[6] S. K. Laliwala, V. N. Mehta, J. V. Rohit, and S. K. Kailasa, "Citrate-modified silver nanoparticles as a colorimetric probe for simultaneous detection of four triptan-family drugs," Sensors and Actuators B: Chemical, vol. 197, pp. 254-263, 2014.

[7] J. R. Morones, J. L. Elechiguerra, A. Camacho et al., "The bactericidal effect of silver nanoparticles," Nanotechnology, vol. 16, no. 10, pp. 2346-2353, 2005.

[8] E. Navarro, F. Piccapietra, B. Wagner et al., "Toxicity of silver nanoparticles to Chlamydomonas reinhardtii," Environmental Science and Technology, vol. 42, no. 23, pp. 8959-8964, 2008.

[9] C. N. R. Rao, G. U. Kulkarni, P. J. Thomas, and P. P. Edwards, "Metal nanoparticles and their assemblies," Chemical Society Reviews, vol. 29, no. 1, pp. 27-35, 2001.

[10] N. K. Agrawal, R. Agarwal, D. Bhatia et al., "Synthesis of Al and $\mathrm{Ag}$ nanoparticles through ultra-sonic dissociation of thermal evaporation deposited thin films for promising clinical applications as polymer nanocomposite," Advanced Materials Letters, vol. 6, no. 4, pp. 301-308, 2015.

[11] S. Küünal, S. Kutti, P. Rauwel, M. Guha, D. Wragg, and E. Rauwel, "Biocidal properties study of silver nanoparticles used for application in green housing," International Nano Letters, vol. 6, no. 3, pp. 191-197, 2016.

[12] S. M. Roopan, Rohit, G. Madhumitha et al., "Low-cost and eco-friendly phyto-synthesis of silver nanoparticles using Cocos nucifera coir extract and its larvicidal activity," Industrial Crops and Products, vol. 43, no. 5, pp. 631-635, 2013.

[13] S. Ahmed, M. Ahmad, B. L. Swami, and S. Ikram, "A review on plants extract mediated synthesis of silver nanoparticles for antimicrobial applications: a green expertise," Journal of Advanced Research, vol. 7, no. 1, pp. 17-28, 2015.

[14] P. Rauwel, S. Küünal, S. Ferdov, and E. Rauwel, "A review on the green synthesis of silver nanoparticles and their morphologies studied via TEM," Advances in Materials Science and Engineering, vol. 2015, Article ID 682749, 9 pages, 2015.

[15] Q. Zhang, J.-J. Xu, Y. Liu, and H.-Y. Chen, "In-situ synthesis of poly(dimethylsiloxane)-gold nanoparticles composite films and its application in microfluidic systems," Lab on a Chip, vol. 8, no. 2, pp. 352-357, 2008.

[16] R. Lin, R. G. Freemantle, N. M. Kelly, T. R. Fielitz, S. O. Obare, and R. Y. Ofoli, "In situ immobilization of palladium nanoparticles in microfluidic reactors and assessment of their catalytic activity," Nanotechnology, vol. 21, no. 32, p. 32605 , 2010.

[17] G. J. Liu, X. H. Yang, Y. Li, Z. G. Yang, W. Hong, and J. F. Liu, "Continuous flow controlled synthesis of gold nanoparticles using pulsed mixing microfluidic system," Advances in Materials Science and Engineering, vol. 2015, Article ID 160819, 11 pages, 2015.

[18] J. Ma, S. M. Lee, C. Yi, and C. W. Li, "Controllable synthesis of functional nanoparticles by microfluidic platforms for biomedical applications-a review," Lab on a Chip, vol. 17, no. 2, pp. 209-226, 2017.

[19] R. Baber, L. Mazzei, N. T. K. T. Thanh, and A. Gavriilidis, "Synthesis of silver nanoparticles in a microfluidic coaxial flow reactor," RSC Advances, vol. 5, no. 116, pp. 95585-95591, 2015.

[20] S. T. He, Y. L. Liu, and H. Maeda, "Controlled synthesis of colloidal silver nanoparticles in capillary micro-flow reactor," Journal of Nanoparticle Research, vol. 10, no. S1, pp. 209-215, 2008.

[21] L. L. Lazarus, C. T. Riche, B. C. Marin, M. Gupta, N. Malmstadt, and R. L. Brutchey, "Two-phase microfluidic droplet flows of ionic liquids for the synthesis of gold and silver nanoparticles," ACS Applied Materials \& Interfaces, vol. 4, no. 6, pp. 3077-3083, 2012.

[22] C.-H. Yang, L.-S. Wang, S.-Y. Chen et al., "Microfluidic assisted synthesis of silver nanoparticle-chitosan composite microparticles for antibacterial applications," International Journal of Pharmaceutics, vol. 510, no. 2, pp. 493-500, 2016.

[23] L. Xu, J. Peng, M. Yan, D. Zhang, and A.-Q. Shen, "Droplet synthesis of silver nanoparticles by a microfluidic device," Chemical Engineering and Processing: Process Intensification, vol. 102, pp. 186-193, 2016.

[24] K. Sugano, Y. Uchida, O. Ichihashi, H. Yamada, T. Tsuchiya, and O. Tabata, "Mixing speed-controlled gold nanoparticle synthesis with pulsed mixing microfluidic system," Microfluidics and Nanofluidics, vol. 9, no. 6, pp. 1165-1174, 2010.

[25] G. J. Liu, X. H. Yang, J. F. Liu, Z. G. Yang, X. B. Li, and T. Zhao, "Controlled synthesis of gold nanoparticles using pulsed mixing based on piezoelectric actuation," Rare Metal Materials and Engineering, vol. 45, no. 6, pp. 1625-1630, 2016.

[26] P. V. Kamat, A. M. Flumiani, and G. V. Hartland, "Picosecond dynamics of silver nanoclusters: photoejection of electrons and fragmentation," Journal of Physical Chemistry B, vol. 102, no. 17, pp. 3123-3128, 1998.

[27] L. M. Liz-Marzán and I. Ladotouriño, "Reduction and stabilization of silver nanoparticles in ethanol by nonionic surfactants," Langmuir, vol. 12, no. 15, pp. 3585-3589, 1996.

[28] M. O. Mennessier, G. Burki, and J. P. Cordoni, "Synthesis and study of silver nanoparticles," Journal of Chemical Education, vol. 84, no. 2, pp. 322-325, 2007.

[29] J. P. Yang, H. J. Yin, J. J. Jia, and Y. Wei, "Facile synthesis of high-concentration, stable aqueous dispersions of uniform silver nanoparticles using aniline as a reductant," Langmuir, vol. 27, no. 8, pp. 5047-5053, 2011.

[30] B. J. Wiley, T. Herricks, A. Y. Sun, and Y. Xia, "Polyol synthesis of silver nanoparticles: use of chloride and oxygen to promote the formation of single-crystal, truncated cubes and tetrahedrons," Nano Letters, vol. 4, no. 10, pp. 1733-1739, 2004. 


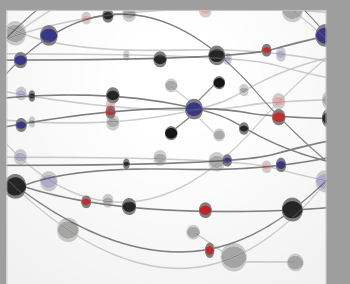

The Scientific World Journal
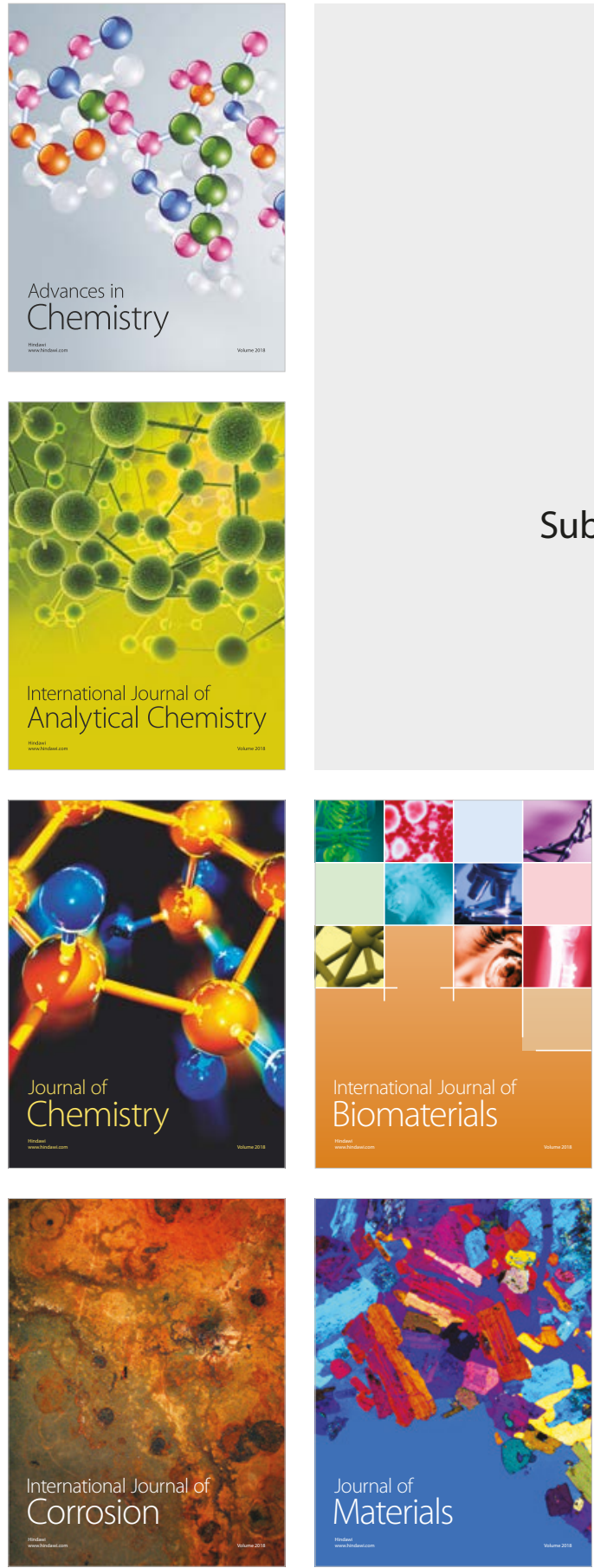

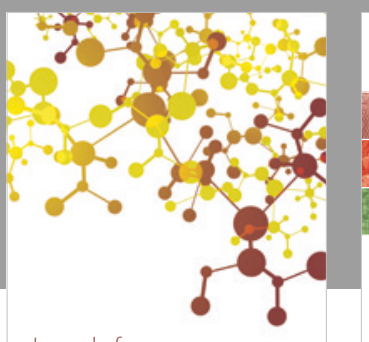

Journal of

Applied Chemistry
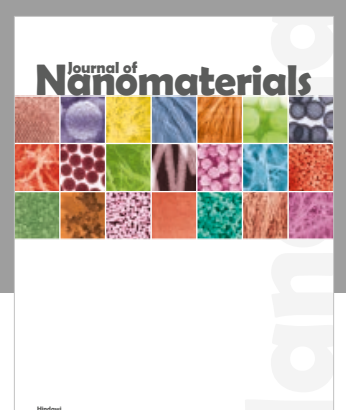

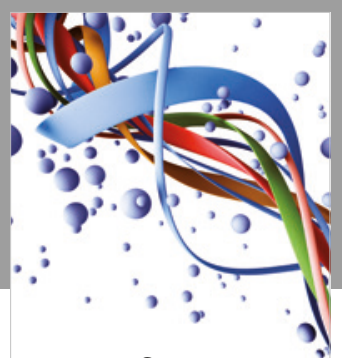

Scientifica

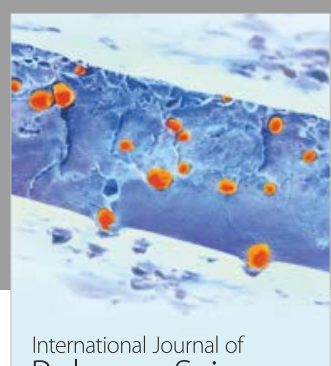

Polymer Science

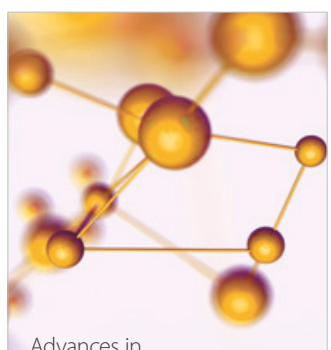

Physical Chemistry
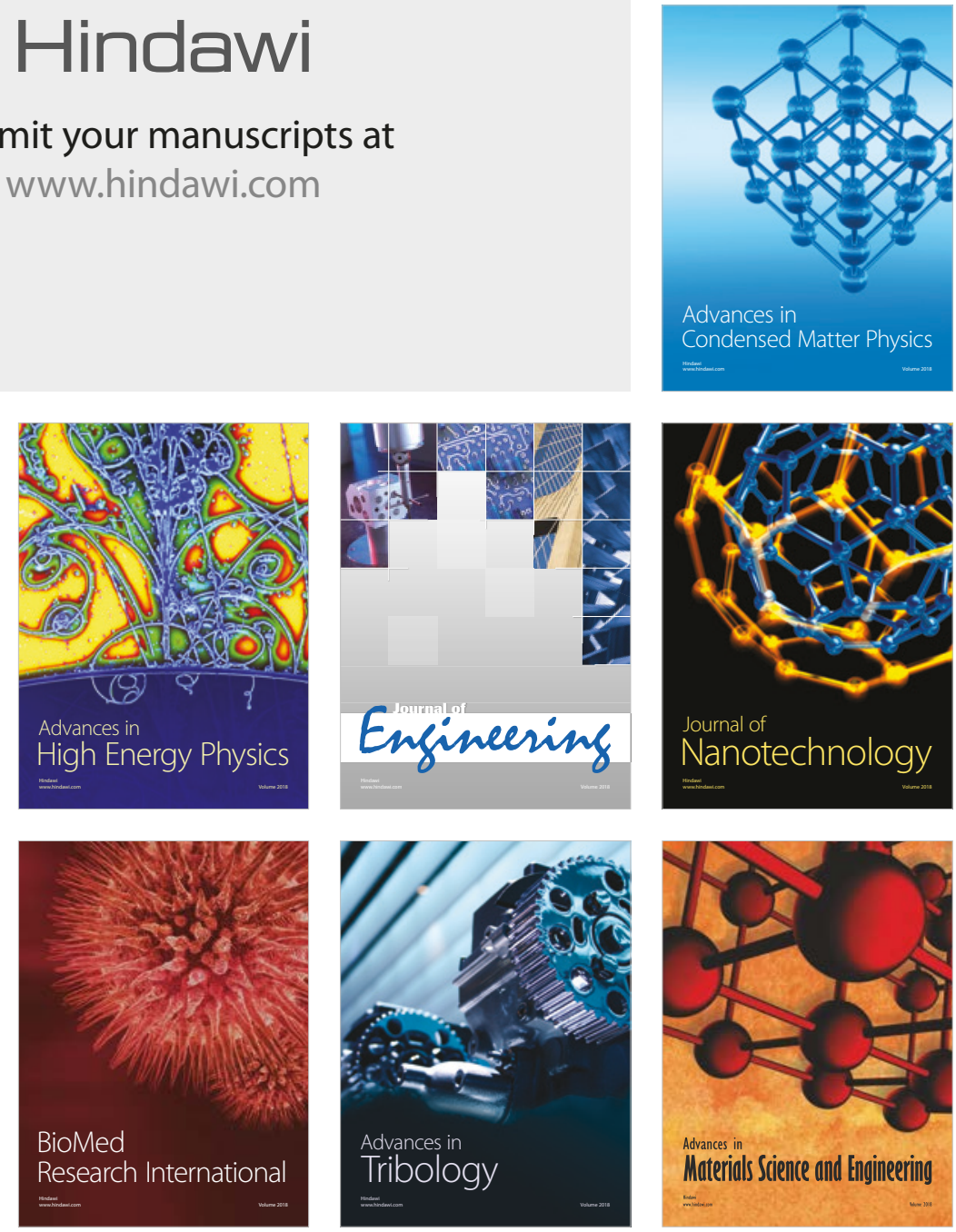